\title{
The Effect Of Educational Program On Critical Care Nurses' Knowledge, Practice And Clinical Outcome Regarding Delirium Among Critically Ill Patients
}

\author{
Gehan A. Younis ${ }^{1}$ and Sabah M. Abo El-Fetoh ${ }^{2}$ \\ ${ }^{1}$ Lecturer of Critical Care Nursing, Faculty of Nursing, Tanta University, ${ }^{2}$ Lecturer of \\ Psychiatric Nursing, Faculty of Nursing, Kafr El-Shiekh University.
}

\begin{abstract}
The Intensive Care Unit is a unique hospital setting, not only because of its physical environment but also because the patients are unstable and submitted to physical and psychological stresses. Delirium is a common disorder in Intensive Care Unit. It is still misdiagnosed by healthcare providers and is treated inappropriately or neglected. Nursing care for delirium includes regular assessment and monitor frequently for at risk patients. The present study aimed to evaluate the effect of educational program on nurses' knowledge, practice and clinical outcome regarding delirium among critically ill patients. The study was conducted at Intensive Care Unit at Tanta University Hospital. It included 40 critical care nurses working in the previously mentioned setting. Also, 40 critically ill patients were used in this study. They divided into two equal groups. 20 critically ill patients were evaluated before implementation of educational program. Another 20 critically ill patients were evaluated after implementation of educational program. Three tools were used in the study for data collection. Instrument 1 is a structure questionnaire sheet. It was divided into two parts; Part A: nurses' socio demographic assessment sheet. Part B: nurse's knowledge assessment sheet, Instrument 2: Observational Checklist and Tool 3: Intensive Care Delirium Screening Checklist (ICDSC). The main results of this study were that, the majority of the studied nurses have good knowledge after educational program. Also, the majority of studied nurses $(97.5 \%)$ have poor score in their practice pre educational program compared to $77.5 \% \%$ of them had good score in their practice post test. Also, about $30 \%$ of pre test group had delirium at 5th, 6 th, and 7 th days of admission compared with $10 \%$ in the post program group. The study recommended that In-services training program should be done continuously for updating critical care nurses' knowledge and practices regarding delirium detection and prevention. Also, Cognitive assessment in general and delirium assessment in particular should be incorporated into nursing education courses.
\end{abstract}

Key words: Delirium, ICU Psychosis, Intensive care Delirium Screening, Checklist $(I C D S C)$

\section{INTRODUCTION}

Delirium is a neuropsychiatric disorder frequently encountered in the Intensive Care Unit (ICU). It is characterized by an acute disturbance of consciousness and attention with cognitive or perceptual changes. Recent studies have reported that delirium is associated with increased length of hospital stay and patient's mortality and increased hospital cost. This condition appears to be largely under diagnosed by nursing and medical staff and associated with poor patient's outcome.
It is estimated that one in every three patients who spends more than five days in an ICU experiences some form of psychotic reaction. Also, it has been estimated that up to $70 \%$ of patients admitted to critical care settings experience Intensive Care Unit psychosis (Gesin G et al., 2012 Dyson 1999). The hospital environment and clinical care system are often iatrogenic for delirium because vulnerable patients are subject to long delirium waiting times, stressful environment associated with multiple staff, disturbed sleep and 
discomfort, dehydration and limited access to food and fluids, immobilization, restricted environment for appropriate care, long waiting times in adverse environment, poor communication, no space for family input (Laura 2008).

Often patients are brought in ICU as emergencies and are without glasses or hearing aids, which limits patients' ability to remain oriented and limit their communication needs (John et al., 2008; Devlin et al., 2011). Causes of ICU delirium can be classified into environmental and medical causes; environmental causes such as sensory deprivation, sleep disturbance and deprivation, continuous lighting, stress and lack of orientation and medical monitoring. Medical Causes such as Pain which is not being adequately controlled in an ICU, critical illness, medication reaction, infection creating fever and toxins in the body, metabolic disturbances as electrolyte imbalance, hypoxia, elevated liver enzymes, heart failure or dehydration (Dyson 1999; Devlin et al., 2011; Riekerk et al., 2009). Patients admitted to an intensive care unit (ICU) may need support with their breathing, circulation, and/or kidneys for varying lengths of time from days to weeks. During that time the patients will receive sedative and analgesic drugs to ensure compliance with artificial ventilation that may affect their memory (van et al., 2009; Devlin et al., 2008; Skrobik and Devlin 2010). Medication administered to patients in ICU such as Opiates, benzodiazepines, propofol, adrenaline, and corticosteroids can all influence memory. In addition, the withdrawal of drugs, such as benzodiazepines, can cause profound withdrawal reactions, which may contribute to delirium. Also, the physical constraints and social isolation experienced by ICU patients and the life-threatening nature of the illness may increase the experience of hallucinations. Delirium thought to be caused by an imbalance of the neurotransmitters dopamine, acetylcholine, and gamma amino butyric acid. The condition is under diagnosed in $60 \%$ of critical care patients and is associated with increased morbidity and mortality (Eijk et al., 2009; Neufeld et al., 2011; Tabet and Howard 2006; Roberts et al., 2007).

ICU delirium has many psychiatric symptoms such as extreme excitement, anxiety, restlessness, hearing voices, clouding of consciousness, hallucinations, nightmares, paranoia, disorientation, agitation, delusions, abnormal behavior, and fluctuating level of consciousness which include aggressive or passive behavior (Tabet and Howard 2006; Pandharipande et al., 2007; Shorr et al., 2006). The treatment of ICU psychosis depends on the causes. The nurse and the physician in charge of the patient along with the pharmacist can work collaboratively to review patient's medications to determine if they may be causing delirium (Kaplan and Sadock's 2007; Keltner 2007; Tyler and 2012). Critical care nurses play an essential role in the management of delirious, critically ill older adults. They are often the interdisciplinary team members who first notice that an elderly patient is experiencing a change in mental status; determine whether the patient is experiencing other indications of distress such as pain, anxiety, or dyspnea that may cause or contribute to the behavioral changes; and intervene by using the best available evidence to promote the comfort, safety, and welfare of the patient (21). Nursing care for delirium includes regular assessment and monitor frequently for at risk patients by using a validated delirium screening tool such as the Intensive Care Delirium Screening Checklist (ICDSC), limit the use of restraints, allow family to visit, reorient the 
patient, ask the family to provide small items such as familiar pictures or the patient's favorite music and allow for normal sleep/wake cycles (Kaplan\& Sadock's 2007; Keltner 2007; Tyler et al., 2012).

Critical care nurse also, Protecting the patient from unnecessary excitement, minimizing shift changes in the nursing staff caring for a patient, orienting the patient to the date and time, reviewing all medical procedures with an explanation to the patient and family about what to expect, asking the patient if there are any questions or concerns, talking with the family to obtain information regarding religious and cultural beliefs, and coordinating the lighting with the normal day-night cycle (Dyson 1999; Roberts et al., 2007; Kaplan and Sadock's 2007). So, our recent study aimed to improve critical care nurses' knowledge and their practice regarding delirium and evaluate critically ill patients' outcome.

\section{Purpose of the study}

To the effect of educational program on nurses' knowledge and practice and clinical outcome regarding delirium among critically ill patients.

\section{Research hypotheses}

1- An improvement in nurses' knowledge and practice regarding delirium will be observed after implementation of educational program of delirium.

2- A positive patient's outcome will be observed after implementation of educational program.

\section{Materials}

\section{Research design}

The research was a quasi-experimental design.

\section{Setting}

The study was carried out in intensive care unit at Tanta Emergency Hospital at Tanta University. The unit consists of three words. Each ward consists of 6 beds.

\section{Sample}

1) All critical care nurses (40 nurse) working in intensive care unit at the time of the study.

2) A convenient sample of 40 critically ill patients newly admitted to ICU and meeting all inclusion criteria were included in the study. The sample was divided into two equal groups:

Pretest group: it consisted of 20 critically ill patients and was evaluated before implementation of educational program and at the period of nurses' pre- test.

Posttest group: it consisted of 20 critically ill patients and was evaluated after one month from implementation of educational program and at the period of nurses' post- test.

\section{Inclusion criteria}

1- Newly admitted patients and willing to participate in the study.

2- Patients with no neurological impairment at the time of admission.

3- No impairment in level of consciousness.

\section{Exclusion criteria}

- Presence of conditions preventing delirium assessment as coma or severe hearing disability.

- Patients admitted with primary neurological conditions or injury.

\section{Instruments:}

Three instruments were used in the study.

Instrument one: Structure

Questionnaire Sheet: 
This instrument was divided into two parts.

Part A: Nurse's Social Characteristics. This part used to assess nurse's socio demographic data such as age, level of education, job, and years of experience.

Part B: Nurse's Knowledge Assessment sheet: This part was developed by the researcher. It was used to assess nurses' knowledge regarding delirium such as definition of delirium, causes and predisposing factors, types of delirium, signs and symptoms of each type, treatment of delirium, negative impact of delirium and measures to prevent it (Roberts et al., 2005).

\section{Instrument two: Observational} Checklist

This instrument was developed by the researcher after literature review. It was used to assess nurses' practice when caring for critically ill patients in intensive care unit to prevent and manage delirium. It included initial assessment of critically ill patients on admission, assessment every shift, neurological assessment, methods of assessment, ways of communication with patients in ICU, and routine nursing care for critically ill patients to prevent delirium.

Instrument three: Intensive Care Delirium Screening Checklist

(ICDSC): (Evaluation of

Performance Outcome):

It was developed by Smith (2010) and Gesin and Devlin, 2012). It was used to assess patients on admission and every shift for one week from their admission to identify patients with delirium. ICDSC tool is an eight items list includes assessment of level of consciousness, attentiveness, and orientation, the presence of hallucination, agitation, inappropriate speech, sleep disturbances, and symptom fluctuation. The score rated from 0 - 8 with score of 4 or greater means that patient has delirium.
Scoring system: The questionnaire consisted of 12 items of true and false questions to assess the knowledge and another 26 items checklist of done and not done to assess the practice were provided. Score +1 for a correct answer, Zero for an incorrect answer was considered. The total scores of questionnaire were less than $50 \%$ was graded as poor, $50 \%$ to less than $75 \%$ score was graded as moderate, and more than $75 \%$ score was graded as good.

\section{Methods}

1. A permission to carry out the study was obtained from responsible authorities.

2. Nurses' and Patient's confidentiality were ascertained.

3. The tools of the study were developed after review of literature.

4. The questionnaire sheet was developed by the researcher to assess the nurses' basic knowledge related to delirium as a pre test before implementation of educational program.

5. Validity of intensive care delirium screening checklist (tool III) is $99 \%$ and its reliability is $79 \%$ (Devlin $\mathrm{J}$ et al., 2007).

6. A pilot study was conducted on 5 critically ill patients to test the applicability of the tools.

7. Data were collected over a period of 6 months starting from July 2013 to February 2014.

8. A pre test was carried out individually for each nurse to assess nurse's knowledge regarding delirium (instrument one). The time taken for pre test evaluation was 0ne hr.

9. An observational checklist (tool II) was carried out individually before implementation of educational program to evaluate the nurses' practice regarding delirium in intensive care unit. 
10. Intensive Care Delirium Screening Checklist (ICDSC) (tool III) was carried out for pre test group before implementation of educational program to evaluate the critically ill patient's outcome. Every patient was assessed from first day of admission until the 7th day of admission. In this tool, the researcher observed each patient individually along with the three nursing shifts and recorded any abnormalities. The total score of this checklist for each day was recorded by the researcher.

11. Educational program was developed by the researcher based on literature review and the results of pretest evaluation for nurses and carried out for all nurses in educational class room in the intensive care unit. The program consisted of two sessions for two consecutive days. Every session took approximately one hour.

Session one of program consisted of aim of the research study, introduction about critically ill patients and effect of delirium, definition of delirium, causes, and predisposing factors of delirium, types of delirium, signs and symptoms of delirium, methods of assessing delirium

Session two of educational program consisted of management strategies for delirium, nursing role to prevent delirium in critically ill patient, and summary of the educational program.

12. Teaching methods were including group discussion with power point media. Teaching media were hand out and illustrative graphs.

13. Posttest evaluation was carried out for all critical care nurses after one moth from implementation of program by using tool (I) part (B). Each nurse was interviewed for reassessment of basic knowledge about delirium. The time taken for posttest evaluation was one hour for each nurse.
14. An observational checklist (instrument two) was carried out individually after implementation of educational program (posttest) to evaluate the nurses' practice regarding delirium in intensive care unit.

15. Intensive care delirium screening checklist (ICDSC) (tool three) was carried out for posttest group after implementation of educational program to evaluate the impact of educational program on critically ill patients' outcome. Every patient was assessed by the researcher from first day of admission until 7th day of admission along with the three nursing shift. The total score of this checklist for each day was recorded.

\section{Statistical analysis}

The analysis was performed using statistical software SPSS version 16.

For quantitative data, the range, mean and standard deviation were calculated. For qualitative data, a comparison between one group before and after intervention was done by using Chisquare test $\left(\chi^{2}\right)$. For comparison between means of one group before and after intervention, paired t-test was used. A significance was adopted at $\mathrm{P}<0.05$ for interpretation of results of tests of significance.

\section{Results}

Table (1) represented the distribution of the studied nurses by their sociodemographic characteristics. The table showed that, the age of the studied nurses ranged from 60-84 years, with a mean age of $1.28 \pm 0.452$ years. As regards the level of education, all studied nurses had bachelor's degree.

In relation to nurse's job, the majority of nurses $(77.5 \%)$ were bedside nurse. Also, this table revealed that three quarters of nurses $(75 \%)$ having 5 years or more of experience. 
Table (2) showed Comparison between studied nurses in relation to mean score of their knowledge about delirium before and after

implementation of educational program. In this table, a significant relation between the mean of the studied nurses pre and post educational program was observed regarding items of definition of delirium, Causes of delirium, Clinical manifestation, Characteristics of hyperactive delirium, Characteristics of hyperactive delirium, types of delirium, Complication of delirium, other risk factors of delirium, Causes of delirium in ICU $\mathrm{P}=0.000^{*}, 0.00^{*}, 0.00^{*}$, $0.002^{*}, 0.00^{*}, 0.002^{*}, 0.008^{*}, 0.00^{*}$ respectively.

Table (3) represented comparison between total knowledge scores of the studied nurses before and after educational program. This table revealed that, most of the studied nurses $67.5 \%$ had poor score in knowledge pre educational program, while about $52.5 \%$ of them had good knowledge score post program. This table also showed a significant different among the studied nurses per and post program regarding total knowledge score at level of $0.038^{*}$.

Table (4) revealed comparison of nursing practice regarding its mean scores before and after educational program. All items of nursing practice improved after educational program. Also, the mean of total score before program was $4.55 \pm 1.782$ compared with $20.20 \pm 6.144$ after program with P-level $=0.000 *$.

Table (5) showed the comparison of total practice score of the studied nurses before and after educational program about delirium. The study showed that majority of the study nurses $(97.5 \%)$ had poor score in their practice pre educational program, while only $10 \%$ fall in the same category post program, compared while $77.5 \%$ of studied nurses had good score in their practice post program.

Table (6) showed correlation between total knowledge and total practice scores of the studied nurses after the educational program of delirium. The majority of nurses $(77.5 \%)$ had good practice score compared with $52.5 \%$ of them had good knowledge score after educational program. the improvement in total score of knowledge and practice was observed among studied nurses.

Table (7) revealed the relationship between total knowledge and practice scores among studied nurses according to socio demographic data, the result showed a positive correlation between nurses' knowledge and practice with nurses years of experience $\left(\mathrm{P}=0.001^{*}\right)$

Table (8) showed the distribution of studied patients according to their socio demographic data and medical conditions. The mean age of total sample was 48.27. Also, it was observed that about $30 \%$ of total studied patients had poly trauma while $2.5 \%$ of them admitted to the intensive care unit post mastectomy. As regards past history, it was observed that about $17.5 \%$ of total studied patients had heart diseases and $2.5 \%$ of them had diabetes mellitus and liver disease. Also, 2.5\% of them had diabetes mellitus and renal disease.

Table (9) showed the mean score of ICDSC items among critically ill patients before and after educational program of delirium. A significant difference between pre and post test group of patients at $4^{\text {th }}$ and $7^{\text {th }}$ day of admission regarding mean score of disorientation where $\mathrm{P}=(0.016,0.038)$ respectively. Also, a significant changes in mean score of hallucination was observed among studied patients at $7^{\text {th }}$ day of admission where $P=0.038$. As regards inappropriate speech, a significant difference in mean score was observed only at $4^{\text {th }}$ day of admission 
$\mathrm{P}=0.007$. Also, the results revealed a significant different among studied groups in relation to sleep | wake cycle disturbance at both $4^{\text {th }}$ day and $7^{\text {th }}$ day of admission P (0.003 and 0.048) respectively. Symptoms fluctuation was observed among two studied group of patients at $4^{\text {th }}$ and $7^{\text {th }}$ day of admission $P$ (0.001). Also, a change in total intensive care delirium screening checklist mean score was observed at $4^{\text {th }}$ and $7^{\text {th }}$ day of admission with $\mathrm{P}=0.002$ and 0.017 .

Table (10) illustrated the distribution of total ICDSC Score from $1^{\text {st }}$ day of admission until $7^{\text {th }}$ day among critically ill patients before and after implementation of educational program. This table clarified that all studied patients reported the total ICDSC score of less than 4 at the $1^{\text {st }}$ and $2^{\text {nd }}$ day of admission. On the other hand, only about $10 \%$ of pre test group reported total ICDSC score between 4-8 (presences of delirium) at $3^{\text {rd }}$ day.

At $4^{\text {th }}$ day of admission, the results reported that only $25 \%$ of pre test group had total score of ICDSC between 4-8 while no one among post test group reported that. Also, it was observed that about $30 \%$ of pre test group had delirium at $5^{\text {th }}$, 6th, and $7^{\text {th }}$ days of admission compared with $10 \%$ in the post test group of patients.
Table (11) showed distribution of total ICDSC score at $7^{\text {th }}$ day of admission according to medical diagnosis and past history. It was observed that $10 \%$ of pre test group of patients diagnosed as poly trauma had delirium at $7^{\text {th }}$ day of admission. Only $5 \%$ of pre test group diagnosed as respiratory distress and post hip replacement also had delirium. While only $10 \%$ of critically ill patients diagnosed as poly trauma had delirium after educational program (post test group). Also, the results showed that all patients in pre test group diagnosed as delirium at $7^{\text {th }}$ day of admission had past history of diabetes mellitus, renal, liver and heart diseases. Only 5\% of them diagnosed as delirium had no past history of any disease. Also, about $10 \%$ of post test group of patients that had delirium had past history of diabetes mellitus, liver disease and hypertension. Table (12) showed the effect of age and sex on total ICDSC score on $7^{\text {th }}$ day of admission among critically ill patients. The results clarified that $20 \%$ of pre test group diagnosed as delirium was male and $10 \%$ of them was female. While, $10 \%$ of post test group diagnosed as delirium was male. As regards age, it was observed that all patients in post test group diagnosed as delirium aged from 40-60 years. Also, all patients in post test group that diagnosed as delirium had the same rang of age.

Table 1. Distribution of the studied nurses according to their sociodemographic

\begin{tabular}{|c|c|c|c|}
\hline \multicolumn{4}{|c|}{ data } \\
\hline \multirow{2}{*}{\multicolumn{2}{|c|}{ Personal characteristics }} & \multicolumn{2}{|c|}{$\begin{array}{c}\text { Studied sample } \\
\quad(\mathrm{n}=\mathbf{4 0})\end{array}$} \\
\hline & & $\mathrm{N}$ & $\%$ \\
\hline \multirow{2}{*}{$\begin{array}{l}\text { Age } \\
\text { (years) }\end{array}$} & From $20-29$ & 29 & 72.5 \\
\hline & From30-40 & 11 & 27.5 \\
\hline \multicolumn{2}{|l|}{ Mean \pm SD } & \multicolumn{2}{|c|}{$1.28 \pm 0.452$} \\
\hline Education & Bacaloruse & 40 & 100 \\
\hline \multirow{2}{*}{ Job } & Nurse & 31 & 77.5 \\
\hline & Supervisor of nursing & 9 & 22.5 \\
\hline \multirow[t]{3}{*}{ Years of experience } & One year or more & 9 & 22.5 \\
\hline & 5 years or more & 30 & 75 \\
\hline & 10 years or more & 1 & 2.5 \\
\hline
\end{tabular}

Table 2. Mean scores of knowledge before and after implementation of educational program among the studied nurses 


\begin{tabular}{|c|c|c|c|c|}
\hline \multirow[b]{2}{*}{ Knowledge items } & \multicolumn{2}{|c|}{ Mean \pm SD } & \multirow[b]{2}{*}{$\mathbf{t}$} & \multirow[b]{2}{*}{$\mathbf{P}$} \\
\hline & $\begin{array}{l}\text { Month } \\
\text { Before }\end{array}$ & $\begin{array}{c}\text { Month } \\
\text { After }\end{array}$ & & \\
\hline 1. Definition of delirium & $0.38 \pm 0.490$ & $0.92 \pm .267$ & 5.448 & $0.000 *$ \\
\hline 2. Causes of delirium & $0.38 \pm 0.490$ & $0.95 \pm 0.221$ & 6.618 & $0.000 *$ \\
\hline 3. Clinical manifestation & $0.22 \pm 0.423$ & $0.90 \pm 0.304$ & 8.122 & $0.000 *$ \\
\hline 4. Characteristics of hyperactive delirium & $0.22 \pm 0.423$ & $0.00 \pm 0.000$ & 3.365 & $0.002 *$ \\
\hline 5. Characteristics of hypoactive delirium & $0.22 \pm 0.423$ & $0.92 \pm 0.267$ & 8.573 & $0.000 *$ \\
\hline 6. types of delirium & $0.18 \pm 0.385$ & $0.28 \pm 0.452$ & 1.275 & 0.210 \\
\hline 7. Complication of delirium & $0.25 \pm 0.439$ & $0.62 \pm 0.490$ & 4.392 & $0.000 *$ \\
\hline 8. risk factors of delirium & $0.15 \pm 0.362$ & $0.08 \pm 0.267$ & 1.000 & 0.323 \\
\hline 9. Other risk factors of delirium & $0.32 \pm 0.474$ & $0.65 \pm 0.483$ & 2.816 & $0.008 *$ \\
\hline 10. Difference between hallucination and delusion & $0.58 \pm 0.501$ & $0.68 \pm 0.474$ & 0.941 & 0.352 \\
\hline 11. Negative impact of delirium & $0.40 \pm 0.496$ & $0.65 \pm 0.483$ & 2.508 & 0.016 \\
\hline 12. Causes of delirium in ICU & $0.10 \pm 0.304$ & $0.82 \pm 0.385$ & 10.140 & $0.000 *$ \\
\hline Total knowledge score & $3.40 \pm 2.687$ & $7.48 \pm 1.935$ & -8.270 & $0.000 *$ \\
\hline
\end{tabular}

Table 3. Total knowledge scores of the studied nurses before and after educational program of delirium:

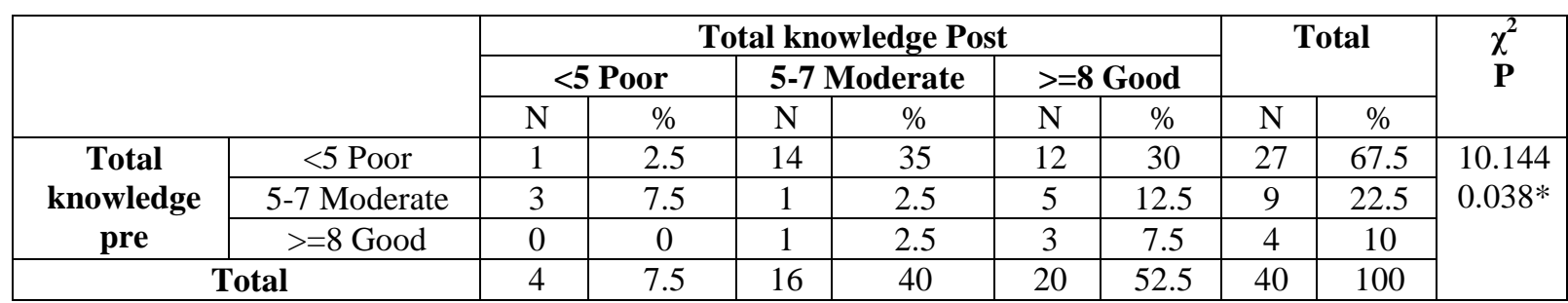

Table 4. Mean scores of studied nurses according to their practice before and after educational program

\begin{tabular}{|c|c|c|c|c|}
\hline \multirow{2}{*}{ Practice items } & \multicolumn{2}{|c|}{ Mean \pm SD } & \multirow{2}{*}{$\mathbf{t}$} & \multirow{2}{*}{$\mathbf{P}$} \\
\hline & Month Before & Month After & & \\
\hline 1. Initial cognitive assessment. & $0.22 \pm 0.423$ & $0.72 \pm 0.452$ & -4.937 & $0.000 *$ \\
\hline 2. Frequent cognitive assessment & $0.08 \pm 0.267$ & $0.85 \pm 0.362$ & -10.218 & $0.000^{*}$ \\
\hline 3. $\quad$ Communication & $0.12 \pm 0.335$ & $0.88 \pm 0.335$ & -10.817 & $0.000^{*}$ \\
\hline 4. Identify patient time & $0.00 \pm 0.000$ & $0.82 \pm 0.385$ & -13.559 & $0.000 *$ \\
\hline 5. Identify patient with location and day & $0.02 \pm 0.158$ & $0.95 \pm 0.221$ & -21.932 & $0.000 *$ \\
\hline 6. $\quad$ Place familiar objects in pt's room & $0.00 \pm 0.000$ & $0.88 \pm 0.335$ & -16.523 & $0.000 *$ \\
\hline $\begin{array}{ll}\text { 7. } & \text { Consistency in staff } \\
\end{array}$ & $0.22 \pm 0.423$ & $0.85 \pm 0.362$ & -8.062 & $0.000 *$ \\
\hline 8. Contact pt's with outside world & $0.12 \pm 0.335$ & $0.78 \pm 0.423$ & -7.093 & $0.000 *$ \\
\hline 9. Feeling of security and orientation by relatives & $0.02 \pm 0.158$ & $0.80 \pm 0.405$ & -11.590 & $0.000 *$ \\
\hline 10. Simplify the care area & $0.08 \pm 0.267$ & $0.80 \pm 0.405$ & -10.140 & $0.000^{*}$ \\
\hline 11. Adequate space between pt's beds & $0.08 \pm 0.267$ & $0.70 \pm 0.464$ & -7.319 & $0.000^{*}$ \\
\hline 12. Using private room & $0.00 \pm .000$ & $0.02 \pm 0.158$ & -1.000 & 0.323 \\
\hline 13. Control source of noise & $0.08 \pm 0.267$ & $0.80 \pm 0.405$ & -10.140 & $0.000 *$ \\
\hline 14. Identify members of treatment teams & $0.08 \pm 0.267$ & $0.90 \pm 0.304$ & -13.559 & $0.000 *$ \\
\hline 15. Correction of sensory impairment & $0.02 \pm 0.158$ & $0.78 \pm 0.423$ & -10.817 & $0.000 *$ \\
\hline 16. Patient participation in treatment & $0.02 \pm 0.158$ & $0.72 \pm 0.452$ & -9.539 & $0.000 *$ \\
\hline 17. Arrangement of treatment time & $0.08 \pm 0.267$ & $0.85 \pm 0.362$ & -9.240 & $0.000 *$ \\
\hline 18. Maintain activity level for ambulated patient & $0.00 \pm 0.000$ & $0.60 \pm 0.496$ & -7.649 & $0.000 *$ \\
\hline 19. Full range of motion exercise for non-ambulatory pt & $0.12 \pm 0.335$ & $0.78 \pm .423$ & -8.510 & $0.000^{*}$ \\
\hline 20. Monitor O2 saturation & $0.92 \pm 0.267$ & $1.00 \pm 0.000$ & -1.778 & 0.083 \\
\hline 21. Monitor BUN, creatinine, soduim, I\&O & $0.92 \pm 0.267$ & $1.00 \pm 0.000$ & -1.778 & 0.083 \\
\hline 22. Monitor BP and HR & $0.92 \pm 0.267$ & $1.00 \pm 0.000$ & -1.778 & 0.083 \\
\hline 23. Follow pain management protocol & $0.10 \pm 0.304$ & $0.45 \pm 0.504$ & -4.149 & $0.000 *$ \\
\hline 24. Reassurance by speaking calmly & $0.20 \pm 0.405$ & $0.82 \pm 0.385$ & -6.750 & $0.000 *$ \\
\hline 25. Inform pt about all activities before implementation & $0.05 \pm 0.221$ & $0.82 \pm 0.385$ & -11.590 & $0.000 *$ \\
\hline 26. Involve family in pt' care & $0.05 \pm 0.221$ & $0.62 \pm 0.490$ & -7.264 & $0.000 *$ \\
\hline Total Skills & $4.55 \pm 1.782$ & $20.20 \pm 6.144$ & -15.807 & $0.000 *$ \\
\hline
\end{tabular}


Gehan A. Younis and Sabah M. Abo El-Fetoh" The Effect Of Educational ..."

Table 5. Total practice scores of the studied nurses before and after educational program of delirium:

\begin{tabular}{|c|c|c|c|c|c|c|c|c|c|c|}
\hline & \multicolumn{6}{|c|}{ Total practice Post program } & \multirow{2}{*}{\multicolumn{2}{|c|}{ Total }} & \\
\hline & & \multicolumn{2}{|c|}{$\begin{array}{c}<9 \\
\text { Poor }\end{array}$} & \multicolumn{2}{|c|}{$\begin{array}{c}9-18 \\
\text { Moderate }\end{array}$} & \multicolumn{2}{|c|}{$\begin{array}{l}>=19 \\
\text { Good }\end{array}$} & & & \\
\hline & & $\mathrm{N}$ & $\%$ & $\mathrm{~N}$ & $\%$ & $\mathrm{~N}$ & $\%$ & $\mathrm{~N}$ & $\%$ & \\
\hline \multirow{2}{*}{$\begin{array}{c}\text { Total practice pre } \\
\text { program }\end{array}$} & $<9$ Poor & 4 & 10 & 5 & 12.5 & 30 & 75 & 39 & 97.5 & \multirow{3}{*}{$\begin{array}{l}0.298 \\
0.862\end{array}$} \\
\hline & 9-18 Moderate & 0 & 0 & 0 & 0 & 1 & 2.5 & 1 & 2.5 & \\
\hline \multicolumn{2}{|c|}{ Total } & 4 & 10 & 5 & 12.5 & 31 & 77.5 & 40 & 100 & \\
\hline
\end{tabular}

Table 6. Correlation between total knowledge and total practice scores of the studied nurses after the educational program of delirium

\begin{tabular}{|c|c|c|c|c|c|c|c|c|c|c|}
\hline & \multicolumn{6}{|c|}{ Total practice post } & \multirow{2}{*}{\multicolumn{2}{|c|}{ Total }} & \multirow{3}{*}{$\begin{array}{l}\chi^{2} \\
\mathbf{P}\end{array}$} \\
\hline & & \multicolumn{2}{|c|}{$\begin{array}{l}<9 \\
\text { Poor }\end{array}$} & \multicolumn{2}{|c|}{$\begin{array}{c}9-18 \\
\text { Moderate }\end{array}$} & \multicolumn{2}{|c|}{$\begin{array}{l}>=19 \\
\text { Good }\end{array}$} & & & \\
\hline & & $\mathbf{N}$ & $\%$ & $\mathbf{N}$ & $\%$ & $\mathbf{N}$ & $\%$ & $\mathbf{N}$ & $\%$ & \\
\hline \multirow{3}{*}{$\begin{array}{c}\text { Total } \\
\text { knowledge post }\end{array}$} & $<5$ Poor & 0 & 0 & 0 & 0 & 3 & 7.5 & 3 & 7.5 & \multirow{4}{*}{$\begin{array}{l}1.815 \\
0.770\end{array}$} \\
\hline & 5-7 Moderate & 2 & 5 & 3 & 7.5 & 11 & 27.5 & 16 & 40 & \\
\hline & $>=8 \mathrm{Good}$ & 2 & 5 & 2 & 5 & 17 & 42.5 & 21 & 52.5 & \\
\hline \multicolumn{2}{|c|}{ Total } & 4 & 10 & 5 & 12.5 & 31 & 77.5 & 40 & 100 & \\
\hline
\end{tabular}

Table 7. Correlation between total knowledge and total practice among studied nurses before and after educational program according to sociodemographic data

\begin{tabular}{|c|c|c|c|c|c|c|c|c|}
\hline \multirow{2}{*}{$\begin{array}{c}\text { Nurses' } \\
\text { characteristics }\end{array}$} & \multicolumn{4}{|c|}{ Total knowledge } & \multicolumn{4}{c|}{ Total practice } \\
\cline { 2 - 9 } & \multicolumn{2}{|c|}{ Pre } & \multicolumn{2}{c|}{ Post } & \multicolumn{3}{c|}{ Pre } & \multicolumn{3}{c|}{ Post } \\
\cline { 2 - 9 } & R & P & R & P & R & P & R & P \\
\hline Age & 0.051 & 0.756 & 0.316 & $0.047^{*}$ & 0.161 & 0.322 & 0.192 & 0.235 \\
\hline Job & -0.487 & $0.001^{*}$ & -0.009 & 0.958 & 0.002 & 0.992 & 0.051 & 0.753 \\
\hline Years of experience & 0.160 & 0.323 & 0.063 & 0.700 & 0.112 & 0.493 & 0.401 & $0.001^{*}$ \\
\hline
\end{tabular}

Table 8. Distribution of the studied patients according to their sociodemographic data and medical conditions

\begin{tabular}{|c|c|c|c|c|c|c|c|c|}
\hline \multirow{2}{*}{\multicolumn{2}{|c|}{ Sociodemographic data }} & \multicolumn{2}{|c|}{$\begin{array}{c}\text { Control group } \\
(\mathrm{n}=20)\end{array}$} & \multicolumn{2}{|c|}{$\begin{array}{c}\text { Study group } \\
(\mathbf{n}=\mathbf{2 0})\end{array}$} & \multicolumn{2}{|c|}{$\begin{array}{c}\text { Total } \\
(\mathbf{n}=40)\end{array}$} & \multirow{2}{*}{$\begin{array}{l}\chi^{2} \\
\mathbf{P}\end{array}$} \\
\hline & & $\mathbf{N}$ & $\%$ & $\mathbf{N}$ & $\%$ & $\mathbf{N}$ & $\%$ & \\
\hline \multirow{2}{*}{ Age } & From $20-40$ & 2 & 10 & 4 & 20 & 6 & 15 & \multirow{3}{*}{$\begin{array}{l}0.784 \\
0.376\end{array}$} \\
\hline & From $41-60$ & 18 & 90 & 16 & 80 & 34 & 85 & \\
\hline \multicolumn{2}{|r|}{ Mean \pm SD } & \multicolumn{2}{|c|}{$47.80 \pm 9.11$} & \multicolumn{2}{|c|}{$48.75 \pm 6.98$} & \multicolumn{2}{|c|}{$48.27 \pm 8.026$} & \\
\hline \multirow{2}{*}{ Sex } & Male & 15 & 75 & 13 & 65 & 28 & 70 & 0.476 \\
\hline & Female & 5 & 25 & 7 & 35 & 12 & 30 & \multirow{8}{*}{$\begin{array}{l}0.490 \\
3.844 \\
0.698\end{array}$} \\
\hline \multirow{7}{*}{$\begin{array}{c}\text { Medical } \\
\text { diagnosis }\end{array}$} & Acute abdomen & 4 & 20 & 5 & 25 & 9 & 22.5 & \\
\hline & Poly trauma & 5 & 25 & 7 & 35 & 12 & 30 & \\
\hline & Myasthenia graves & 2 & 10 & 3 & 15 & 5 & 12.5 & \\
\hline & COPD & 3 & 15 & 2 & 10 & 5 & 12.5 & \\
\hline & Respiratory distress & 3 & 15 & 1 & 5 & 4 & 10 & \\
\hline & Post hip replacement & 3 & 15 & 1 & 5 & 4 & 10 & \\
\hline & Post mastectomy & 0 & 0 & 1 & 5 & 1 & 2.5 & \\
\hline \multirow{12}{*}{$\begin{array}{c}\text { Past } \\
\text { history }\end{array}$} & No past history & 3 & 15 & 0 & 0 & 3 & 7.5 & \multirow{12}{*}{$\begin{array}{l}11.143 \\
0.431\end{array}$} \\
\hline & DM & 1 & 5 & 0 & 0 & 1 & 2.5 & \\
\hline & Hypertension & 2 & 10 & 3 & 15 & 5 & 12.5 & \\
\hline & DM \& Hypertension & 3 & 15 & 3 & 15 & 6 & 15 & \\
\hline & Renal disease & 0 & 0 & 2 & 10 & 2 & 5 & \\
\hline & Hypertension \& Renal disease & 1 & 5 & 2 & 10 & 3 & 7.5 & \\
\hline & DM \& Renal disease & 1 & 5 & 0 & 0 & 1 & 2.5 & \\
\hline & Heart disease & 4 & 20 & 3 & 15 & 7 & 17.5 & \\
\hline & DM \& Heart disease & 2 & 10 & 1 & 5 & 3 & 7.5 & \\
\hline & Liver disease & 1 & 5 & 4 & 20 & 5 & 12.5 & \\
\hline & DM \& Liver disease & 1 & 5 & 0 & 0 & 1 & 2.5 & \\
\hline & DM , Hypertension \& Liver disease & 1 & 5 & 2 & 10 & 3 & 7.5 & \\
\hline
\end{tabular}


Table 9. Mean score of ICDSC items among critically ill patients before and after educational program:

\begin{tabular}{|c|c|c|c|c|c|}
\hline \multirow{2}{*}{\multicolumn{2}{|c|}{ ICDSC items at $4^{\text {th }}$ day and $7^{\text {th }}$ day }} & \multicolumn{2}{|c|}{ Mean \pm SD } & \multirow{3}{*}{$\begin{array}{c}\mathbf{F} \\
0.345\end{array}$} & \multirow{3}{*}{$\frac{\mathbf{P}}{0.560}$} \\
\hline & & Control group & Study group & & \\
\hline \multirow{2}{*}{ 1. Altered level of consciousness } & $4^{\text {th }}$ day & $0.10 \pm 0.308$ & $0.05 \pm 0.224$ & & \\
\hline & $7^{\text {th }}$ day & $0.30 \pm 0.470$ & $0.10 \pm 0.308$ & 2.533 & 0.120 \\
\hline \multirow[t]{2}{*}{ 2. Inattention } & $4^{\text {th }}$ day & $0.15 \pm 0.366$ & $0.00 \pm 0.000$ & 3.353 & 0.075 \\
\hline & $7^{\text {th }}$ day & $0.30 \pm 0.470$ & $0.10 \pm 0.308$ & 2.533 & 0.120 \\
\hline \multirow[t]{2}{*}{ 3. Disorientation } & $4^{\text {th }}$ day & $0.25 \pm 0.444$ & $0.00 \pm 0.000$ & 6.333 & $0.016^{*}$ \\
\hline & $7^{\text {th }}$ day & $0.30 \pm 0.470$ & $0.05 \pm 0.224$ & 4.612 & $0.038^{*}$ \\
\hline \multirow[t]{2}{*}{ 4. $\quad$ Hallucination } & $4^{\text {th }}$ day & $0.15 \pm 0.366$ & $0.00 \pm 0.000$ & 3.353 & 0.075 \\
\hline & $7^{\text {th }}$ day & $0.30 \pm 0.470$ & $0.05 \pm .224$ & 4.612 & $0.038^{*}$ \\
\hline \multirow{2}{*}{ 5. Psychomotor agitation } & $4^{\text {th }}$ day & $0.15 \pm 0.366$ & $0.05 \pm 0.224$ & 1.086 & 0.304 \\
\hline & $7^{\text {th }}$ day & $0.30 \pm .470$ & $0.10 \pm .308$ & 2.533 & 0.120 \\
\hline \multirow[t]{2}{*}{ 6. inappropriate speech } & $4^{\text {th }}$ day & $0.30 \pm 0.470$ & $0.00 \pm 0.000$ & 8.143 & $0.007 *$ \\
\hline & $7^{\text {th }}$ day & $0.30 \pm .470$ & $0.10 \pm .308$ & 2.533 & 0.120 \\
\hline \multirow[t]{2}{*}{ 7. Sleep/wake cycle disturbance } & $4^{\text {th }}$ day & $0.85 \pm 0.366$ & $0.40 \pm 0.503$ & 10.469 & $0.003^{*}$ \\
\hline & $7^{\text {th }}$ day & $0.80 \pm .410$ & $0.50 \pm .513$ & 4.171 & $0.048 *$ \\
\hline \multirow[t]{2}{*}{ 8. Symptoms fluctuation } & $4^{\text {th }}$ day & $0.85 \pm 0.366$ & $0.35 \pm 0.489$ & 13.380 & $0.001 *$ \\
\hline & $7^{\text {th }}$ day & $0.80 \pm .410$ & $0.30 \pm .470$ & 12.838 & $0.001 *$ \\
\hline \multirow{2}{*}{$\begin{array}{l}\text { Total Intensive Care Delirium } \\
\text { Screening Checklist (ICDSC) }\end{array}$} & $4^{\text {th }}$ day & $2.80 \pm 2.353$ & $0.85 \pm 0.988$ & 11.676 & $0.002 *$ \\
\hline & $7^{\text {th }}$ day & $3.40 \pm 3.185$ & $1.30 \pm 2.029$ & 6.184 & $0.017 *$ \\
\hline
\end{tabular}

Table 10. Distribution of total ICDSC scores from $1^{\text {st }}$ day of admission until $7^{\text {th }}$ day among critically ill patients before and after implementation of educational

\section{program}

\begin{tabular}{|c|c|c|c|c|c|c|c|}
\hline \multicolumn{2}{|c|}{ Total ICDSC Score } & \multicolumn{2}{|c|}{$\begin{array}{c}\text { Control group (Pre } \\
\text { program) }(n=20)\end{array}$} & \multicolumn{2}{|c|}{$\begin{array}{c}\text { Study group (Post } \\
\text { program) }(\mathrm{n}=20)\end{array}$} & \multirow[t]{2}{*}{$\chi^{2}$} & \multirow[t]{2}{*}{$\mathbf{P}$} \\
\hline & & $\mathrm{N}$ & $\%$ & $\mathrm{~N}$ & $\%$ & & \\
\hline \multirow{2}{*}{$\begin{array}{l}\text { Total ICDSC score } 1^{\text {st }} \\
\text { day of admission }\end{array}$} & $<4$ absence of delirium & 20 & 100 & 20 & 100 & & \\
\hline & 4-8 "presence delirium" & 0 & 0 & 0 & 0 & & \\
\hline \multirow{2}{*}{$\begin{array}{l}\text { Total ICDSC Score } 2^{\text {nd }} \\
\text { day of admission }\end{array}$} & $<4$ "absence of delirium" & 20 & 100 & 20 & 100 & \multirow[t]{2}{*}{ - } & \multirow[t]{2}{*}{ - } \\
\hline & 4-8 "presence delirium" & 0 & 0 & 0 & 0 & & \\
\hline \multirow{2}{*}{$\begin{array}{l}\text { Total ICDSC Score } 3^{\text {rd }} \\
\text { day of admission }\end{array}$} & $<4$ "absence of delirium" & 18 & 90 & 20 & 100 & \multirow{2}{*}{$\begin{array}{c}2.10 \\
5\end{array}$} & \multirow[t]{2}{*}{0.147} \\
\hline & 4-8 "presence delirium" & 2 & 10 & 0 & 0 & & \\
\hline \multirow{2}{*}{$\begin{array}{c}\text { Total ICDSC Score } 4^{\text {th }} \\
\text { day of admission }\end{array}$} & $<4$ "absence of delirium" & 15 & 75 & 20 & 100 & \multirow{2}{*}{$\begin{array}{c}5.71 \\
4\end{array}$} & \multirow{2}{*}{$\begin{array}{c}0.017 \\
*\end{array}$} \\
\hline & 4-8 "presence delirium" & 5 & 25 & 0 & 0 & & \\
\hline \multirow{2}{*}{$\begin{array}{l}\text { Total ICDSC Score } 5^{\text {th }} \\
\text { day of admission }\end{array}$} & $<4$ "absence of delirium" & 14 & 70 & 19 & 95 & \multirow{2}{*}{$\begin{array}{c}4.32 \\
9\end{array}$} & \multirow{2}{*}{$\begin{array}{c}0.037 \\
*\end{array}$} \\
\hline & 4-8 "presence delirium" & 6 & 30 & 1 & 5 & & \\
\hline \multirow{2}{*}{$\begin{array}{l}\text { Total ICDSC Score } 6^{\text {th }} \\
\text { day of admission }\end{array}$} & $<4$ "absence of delirium" & 14 & 70 & 18 & 90 & \multirow{2}{*}{$\begin{array}{c}2.50 \\
0\end{array}$} & \multirow[t]{2}{*}{0.114} \\
\hline & 4-8 "presence delirium" & 6 & 30 & 2 & 10 & & \\
\hline \multirow{2}{*}{$\begin{array}{l}\text { Total ICDSC Score } 7^{\text {th }} \\
\text { day of admission }\end{array}$} & $<4$ "absence of delirium" & 14 & 70 & 18 & 90 & \multirow{2}{*}{$\begin{array}{c}2.50 \\
0 \\
\end{array}$} & \multirow[t]{2}{*}{0.114} \\
\hline & 4-8 "presence delirium" & 6 & 30 & 2 & 10 & & \\
\hline
\end{tabular}

Table 11. Distribution of total ICDSC score at the 7th day of admission according to medical diagnosis and past history among critically ill patients

\begin{tabular}{|c|c|c|c|c|c|c|c|c|c|}
\hline \multirow{3}{*}{\multicolumn{2}{|c|}{ Total ICDSC 7th day }} & \multicolumn{4}{|c|}{ Control group $(\mathbf{n}=\mathbf{2 0})$} & \multicolumn{4}{|c|}{ Study group $(\mathrm{n}=\mathbf{2 0})$} \\
\hline & & \multicolumn{2}{|c|}{$\begin{array}{c}<4 \text { "No } \\
\text { delirium" }\end{array}$} & \multicolumn{2}{|c|}{$\begin{array}{c}4-8 \\
\text { Delirium } \\
\end{array}$} & \multicolumn{2}{|c|}{$<4$ "No delirium" } & \multicolumn{2}{|c|}{$\begin{array}{c}4-8 \\
\text { "Delirium } \\
\end{array}$} \\
\hline & & $\mathrm{N}$ & $\%$ & $\mathrm{~N}$ & $\%$ & $\mathrm{~N}$ & $\%$ & $\mathrm{~N}$ & $\%$ \\
\hline \multirow{9}{*}{$\begin{array}{l}\text { Medical } \\
\text { diagnosis }\end{array}$} & Acute abdomen & 2 & 10 & 2 & 10 & 5 & 25 & 0 & 0 \\
\hline & Poly trauma & 3 & 15 & 2 & 10 & 5 & 25 & 2 & 10 \\
\hline & Myasthenia graves & 2 & 10 & 0 & 0 & 3 & 15 & 0 & 0 \\
\hline & COPD & 3 & 15 & 0 & 0 & 2 & 10 & 0 & 0 \\
\hline & Respiratory distress & 2 & 10 & 1 & 5 & 1 & 5 & 0 & 0 \\
\hline & Post hip replacement & 2 & 10 & 1 & 5 & 1 & 5 & 0 & 0 \\
\hline & Post mastectomy & 0 & 0 & 0 & 0 & 1 & 5 & 0 & 0 \\
\hline & Total & 14 & 70 & 6 & 30 & 18 & 90 & 2 & 10 \\
\hline & $\chi^{2}, P$ & \multicolumn{4}{|c|}{$3.175,0.673$} & \multicolumn{4}{|c|}{$4.127,0.659$} \\
\hline Past & No past history & 2 & 10 & 1 & 5 & 0 & 0 & 0 & 0 \\
\hline
\end{tabular}


Gehan A. Younis and Sabah M. Abo El-Fetoh" The Effect Of Educational ..."

\begin{tabular}{|c|c|c|c|c|c|c|c|c|c|}
\hline \multirow[t]{13}{*}{ history } & DM & 1 & 5 & 0 & 0 & 0 & 0 & 0 & 0 \\
\hline & Hypertension & 2 & 10 & 0 & 0 & 2 & 10 & 1 & 5 \\
\hline & DM \& Hypertension & 2 & 10 & 1 & 5 & 3 & 15 & 0 & 0 \\
\hline & Hypertension \& Renal disease & 1 & 5 & 0 & 0 & 2 & 10 & 0 & 0 \\
\hline & DM \& Renal disease & 1 & 5 & 0 & 0 & 0 & 0 & 0 & 0 \\
\hline & Heart disease & 3 & 15 & 1 & 5 & 3 & 15 & 0 & 0 \\
\hline & DM \& Heart disease & 1 & 5 & 1 & 5 & 1 & 5 & 0 & 0 \\
\hline & Liver disease & 1 & 5 & 0 & 0 & 4 & 20 & 0 & 0 \\
\hline & DM \& Liver disease & 0 & 0 & 1 & 5 & 0 & 0 & 0 & 0 \\
\hline & $\begin{array}{l}\text { DM, Hypertension \& Liver } \\
\text { disease }\end{array}$ & 0 & 0 & 1 & 5 & 1 & 5 & 1 & 5 \\
\hline & Renal disease & 0 & 0 & 0 & 0 & 2 & 10 & 0 & 0 \\
\hline & Total & 14 & 70 & 6 & 30 & 18 & 90 & 2 & 10 \\
\hline & $\chi^{2}, P$ & \multicolumn{4}{|c|}{$7.698,0.658$} & \multicolumn{4}{|c|}{$7.037,0.425$} \\
\hline
\end{tabular}

Table 12. The effect of sex and age on total ICDSC score on 7th day of admission among critically ill patients

\begin{tabular}{|c|c|c|c|c|c|c|c|c|c|}
\hline \multirow{3}{*}{\multicolumn{2}{|c|}{$\begin{array}{l}\text { Total ICDSC (1-8) } \\
7^{\text {th }} \text { day of admission }\end{array}$}} & \multicolumn{4}{|c|}{ Control group $(n=20)$} & \multicolumn{4}{|c|}{ Study group $(n=20)$} \\
\hline & & \multicolumn{2}{|c|}{$\begin{array}{c}<4 \text { "No } \\
\text { delirium }\end{array}$} & \multicolumn{2}{|c|}{ 4-8 Delirium } & \multicolumn{2}{|c|}{$\begin{array}{c}<4 \text { "No } \\
\text { delirium" }\end{array}$} & \multicolumn{2}{|c|}{$\begin{array}{c}4-8 \\
\text { "Delirium }\end{array}$} \\
\hline & & $\mathrm{N}$ & $\%$ & $\mathrm{~N}$ & $\%$ & $\mathrm{~N}$ & $\%$ & $\mathrm{~N}$ & $\%$ \\
\hline \multirow[t]{2}{*}{ Sex } & Male & 11 & 55 & 4 & 20 & 11 & 55 & 2 & 10 \\
\hline & Female & 3 & 15 & 2 & 10 & 7 & 35 & 0 & 0 \\
\hline \multicolumn{2}{|c|}{ Total } & 14 & 70 & 6 & 30 & 18 & 90 & 2 & 10 \\
\hline \multicolumn{2}{|c|}{$\begin{array}{l}\chi^{2} \\
\mathbf{P}\end{array}$} & \multicolumn{4}{|c|}{$\begin{array}{l}0.317 \\
0.573\end{array}$} & \multicolumn{4}{|c|}{$\begin{array}{l}1.197 \\
0.274\end{array}$} \\
\hline \multirow[t]{2}{*}{ age } & $\begin{array}{l}\text { From 20- } \\
40\end{array}$ & 2 & 10 & 0 & 0 & 4 & 20 & 0 & 0 \\
\hline & $\begin{array}{l}\text { From 41- } \\
60\end{array}$ & 12 & 60 & 6 & 30 & 14 & 70 & 2 & 10 \\
\hline \multicolumn{2}{|c|}{ Total } & 14 & 70 & 6 & 30 & 18 & 90 & 2 & 10 \\
\hline \multicolumn{2}{|c|}{$\begin{array}{l}\chi^{2} \\
\mathbf{P}\end{array}$} & \multicolumn{4}{|c|}{$\begin{array}{l}0.952 \\
0.329\end{array}$} & \multicolumn{4}{|c|}{0.556} \\
\hline
\end{tabular}

\section{Discussion}

Delirium is a significant problem for critical care patients, affecting $50 \%$ of non-ventilated and $80 \%$ of ventilated ICU patients. It is associated with many negative clinical outcomes including increased mortality and morbidity (Puntillo 2007). Critical care nurses are the health care providers who have the opportunity to improve patients 'quality of care and outcome by recognizing delirium early, determining the causes, symptoms, and providing knowledgeable care and continuously monitor critically ill patients (Elfeky and Ali 2013). The aim of this study was to evaluate the effect of educational program on nurses' knowledge and practice regarding delirium among critically ill patient. Regarding nurse's knowledge and practices of delirium, the present study showed a significant improvement in all items of knowledge and practice among studied nurses after educational program and this leads to improvement of patient's outcome and decrease incidence of delirium in ICU at Tanta University hospital.

Also, the mean score of total knowledge and practice was increased among studied nurses after educational program. This contributed that the researcher had enough time, proper environment, suitable learning media and material for teaching these critical care nurses. Also, the educational program focuses on early recognition, proper assessment tool, prevention, and management of delirium. Also, the improvement of nurse's practice depending on improvement of nurse's knowledge. Also, the majority of nurses have more than five years of experience had no an educational program to updating their knowledge and practices. 
Gehan A. Younis and Sabah M. Abo El-Fetoh" The Effect Of Educational ..."

This result agreed with Gail (2012) (Gesin and Devlin 2012) who applied nurses' knowledge of delirium and ability to evaluate It correctly. Also, he illustrated that the critical care nurses can play a key role when delirium screening and educational efforts are being developed and implemented in the ICU. Also, Devlin et al. (2007) revealed that lack of institutional teaching about assessment of delirium is due to a lack of clarity about the optimal way to educate nurses about assessment of delirium or due to decisions about nursing curriculum are made by persons who are either not aware of delirium assessment in the ICU or who think that assessment of delirium is not important.

Also, the findings of the present study revealed that all nurses working as nurse supervisor had poor knowledge and practices before educational program. This may be due to that all nurses supervisors had no time for updating their knowledge and away from direct nursing care for critically ill patients. Regarding to socio-demographic characteristics of studied critically ill patients, the present study revealed that, the majority of the sample (pretest and posttest group) aged from 41-65years. This may contributed that, most of critically ill patients admitted to the intensive care unit are old and have cognitive disorders that may appear as a result of aging process. This results was in agreement with Krahne et al. (2006) they concluded that up to $20 \%$ of hospitalized patients in an intensive care setting older than 65 years.

In relation to medical diagnosis, the results of the present study showed that, most of patients in pre test and post test group diagnosed as poly trauma. This interpreted that the intensive care unit is a place of choice for treating trauma patients. Also, the current result reported that the most of admitted patients to the intensive care unit had past history of diabetes mellitus and heart diseases. This results was in the agreement with Balas et al. (2012), they found that $62 \%$ of the patients had evidence of delirium during the ICU stay. (31) Concerning items of intensive care delirium screening checklist (ICDSC), the present study showed that all studied sample before and after implementation of educational program of delirium had no changes in all items of this screening tool such as altered level of consciousness, inattention, disorientation, hallucination, psychomotor agitation, inappropriate speech, sleep / wake cycle disturbance and symptoms fluctuation starting from the first day until the third day of admission. On the other hand, changes in these items appeared at the fourth day of admission and it increased at the seventh day among pretest group (before implementation of educational program). Also, mean score of all ICDSC items was increased among pretest group. And highly significant difference was observed between pre and posttest group regarding the total 'score of ICDSC. This is may be due to lack of knowledge and practices of critical care nurses in using ICDS assessment tool to detect and prevent delirium had negative effects on critical care patient's outcome. This result was constant with Gesin et al. (2012) they stated that, the use of the ICDSC may improves perceptions and ability of the nurses to evaluate patients correctly for delirium. Also, they illustrated that, critical care pharmacists can play a key role in collaborating with critical care nurses and physicians when delirium screening and educational efforts are being developed and implemented in the ICU.

As regards the incidence of delirium among critically ill patients, the current study revealed that no one in both group (pre and post test group) diagnosed with delirium starting from the first day of admission until the third day. These patients admitted to ICU with no cognitive impairment and had normal level of consciousness as inclusion criteria for the sample. As results of 
Gehan A. Younis and Sabah M. Abo El-Fetoh" The Effect Of Educational ..."

inadequacy of caring for these patients and lack of proper delirium assessment tool, their medical condition was deteriorated gradually. On the other hand, the result reported that, $25 \%$ of critically ill patients in pretest group diagnosed as delirium in the fourth day and the percent increased to $30 \%$ at the fifth, sixth and seventh day of admission. No one in critical care nurses enriched with enough knowledge and practices for dealing with these patients. While small percent of critically ill patients in posttest group diagnosed as delirium. This may be due to the aging process and co- morbidity of their diseases. Educational program for prevention and early detection of delirium learned by the researcher to the critical care nurses had positive effects on patients' outcome among posttest group. This result was in agreement with. Truman and Ely (2003) Dieudonne (2010) and Barr (2013) they illustrated that prevention of delirium focus on non-pharmacological protocol of care as repeatedly reorienting patients, providing cognitive stimulating activities several times a day, using sleep protocol, early mobilization activities, range-of motion exercises, removing catheters and physical restraints in a timely manner and having patients use eye glasses and minimizing unnecessary noise.

Concerning the correlation among medical diagnosis, past history, total ICDSC and presence of delirium, the present study showed that delirious patients that appeared among pretest group (before educational program) diagnosed with poly trauma, acute abdomen, respiratory distress and small percent of them had post total hip replacement surgery. On the other hand, small percent among posttest group (after educational program) with delirium had poly trauma. Also, this result showed that most of delirious patients among pretest group had past history of diabetes mellitus, liver disease, heart diseases and hypertension. While the small percent of delirious patients had no past history. Also, a minority of critically ill patients among posttest group diagnosed with delirium had past history of diabetes, hypertension and liver disease. Past history of diabetes and liver diseases considered predisposing factors for cognitive impairment and may increase the risk of delirium. The result was in accordance with Arend and Christensen (2009) they reported that the majority of ICU psychosis exposed to delirium had a past history of heart disease, metabolic abnormalities, and fluid and electrolytes disturbances. Regarding the effect of sex and age on total ICDSC score, the current study reported that $20 \%$ of patients in pre test group of patients diagnosed as delirium were male and the small percent of delirious patient were female in the same group. While, the minority of the sample among post test group had ICU psychosis were male. In relation to age, all delirious patients among both pre and posttest group were old and aged from 41to 65 years old. This contributed that beside the lack of practices regarding caring for these patients, the aging process also, may affect cognitive function of elderly patients. This result was in line with Flinn et al. (2009) they stated that, delirium is a common postoperative complication among elderly patients, and it contributes significantly to postoperative morbidity and mortality. Also, Brajtman et al. (2011) and Schreier (2010) they concluded that delirium is a clinical condition affecting many older adults at the end of their lives and nearly $90 \%$ of terminally ill patients become delirious before death.

\section{Conclusion}

An improvement in nurses' knowledge and practice regarding delirium was observed after implementation of educational program about delirium. After the implementation of the program, patients had fewer signs of delirium than before the program. 
Gehan A. Younis and Sabah M. Abo El-Fetoh" The Effect Of Educational ..."

\section{Recommendation}

\section{On the educational level}

- Formal assessment skills and lectures about delirium should not only be a part of the post graduate ICU course but taught at under graduate level.

- Educating ICU staff about the conditions that lead to ICU delirium, the early recognition and treatment is essential to good management.

- Incorporating cognitive assessment in general and delirium assessment in particular into nursing education courses.

\section{On the practical level}

- Integration of delirium assessment and management into daily nursing care of critically ill patients.

\section{On the research level}

- More research is needed on the outcomes of delirium and on the use of other delirium assessment tools in standard bedside assessments.

- Further researches is needed on assessing delirium in intubated patient

- In-services training program should be donle continuously to update critical care nurses' knowledge and practices regarding delirium detection and prevention.

- Repetition of the study on a larger number of nurses and patient.

\section{Acknowledgement}

The authors would like to express their sincere gratitude to the hospital administrating team who helped in facilitating conduction of this study. Great appreciation as well is to the critical care nursing staff who accepted to participate in the current study. The authors also acknowledge the patients in Tanta university hospital.

\section{References}

Arend E and Christensen M, Delirium in the intensive care unit: a review. British Association of Critical Care Nurses, Nursing in Critical Care, 2009; 14(3).
Balas M, Rice M, Chaperon C, Smith H, Disbot and Barry M, Management of Delirium in Critically Ill Older Adults, Critical Care Nurse J, 2012;32( 4): 15-25.

Barr J. Clinical Practice Guidelines for the Management of Pain, Agitation, and Delirium in Adult Patients in the Intensive Care Unit. Critical Care Medicine, 2013; 41 (1).

Brajtman S, Wright D, Hogan D and Allard P. Developing Guidelines on the Assessment and Treatment of Delirium in Older Adults at the End of Life. Canadian Geriatrics Journal, 2011;14(2).

Devlin J, Bhat S and Roberts R. Current perceptions and practices surrounding the recognition and treatment of delirium in the intensive care unit: a survey of 250 critical care pharmacists from eight states, Ann Pharmacother, 2011; 45:1217-1229

Devlin J, Fong J, Fraser GLand Riker RR. Delirium assessment in the critically ill. Intensive Care Med, 2007; 33 (6):929-940.

DevlinJ, Marquis $\mathrm{F}$ and Riker R. Combined didactic a d scenariobased education improves the ability of intensive care unit staff to recognize delirium at the bedside, Crit Care, 2008;12:R19.

Dieudonne N. Evaluation and Management of Delirium in the Critically Ill Patient: A Literature Review.

A Master's Project Submitted to the Faculty of the College Of Nursing the University Of Arizona. 2010.

Dyson M. Intensive care unit psychosis, the therapeutic nurse-patient relationship and the influence of the intensive care setting: analyses of interrelating factors. J Clin Nurs. 1999 May;8(3):284-90.

EijkM J, Marum R, Klijn IAM. Comparison of delirium assessment tools in a mixed 
Gehan A. Younis and Sabah M. Abo El-Fetoh" The Effect Of Educational ..."

intensive care unit, Crit Care Med, 2009; 37:1881-1885.

Elfeky H A, Ali FS. Nurses' Practices and Perception of Delirium in the Intensive Care Units of a Selected University Hospitals in Egypt, Journal of Education and Practice, 2013;4(19).

Flinn D, Diehl K, Seyfried L and Malani M. Prevention, Diagnosis, and Management of Postoperative Delirium in Older Adults, $\mathrm{J}$ Am CollSurg,2009; 209(2).

Gaild G, Brittany B, Andrew P, James $H$ and Susan L. Nurses' Knowledge of Delirium and Ability to Evaluate It Correctly

Gesin G, Russsll B, Lin A, Norton H, Evan $S$ and Devlin J. Impact of a Delirium Screening Tool and Multifaceted Education on Nurses' Knowledge of Delirium and Ability to Evaluate It Correctly. American Association of CriticalCare Nurses, 2012; 21(1).

Granberg A, Engberg I B and Lundberg D. Acute confusion and unreal experiences in intensive care patients in relation to the ICU syndrome. Intensive Crit J Care Nurs.1999 Feb;15(1):19-33.

John W, Jeffre J, Elizabeth P, Skrobik Y and John M. Assessment of Delirium in the Intensive Care Unit: Nursing Practices and Perceptions, American Association of Critical-Care Nurses, 2008; 17:555-565.

John W, Jeffrey J. Gilles L,Richard R. Delirium assessment in the critically ill Intensive Care Med 2007, 33: 929-940

Kaplan and Sadock's. Synopsis of Psychiatry: Behavioral Sciences/Clinical Psychiatry, 10th Edition, Lippincott Williams \& Wilkins, I2007; (320- 350).

Keltner N. Psychiatric Nursing. 5th ed. U.S.A :Mosby, 2007; 443-465.

Krahne D, Heymann A, Claudia S. How to monitor delirium in the ICU and why it is important, Clinical
Effectiveness in Nursing, 2006;953: 269-79.

Laura M. Patient Care and Delirium Assessment, American Association of Critical-Care Nurses, 2008; 17:576.

NeufeldK J, HayaM J, Coughlin M. Evaluation of two intensive care delirium screening tools for noncritically ill hospitalized patients. Psychosomatics, 2011; 52:133140.

Pandharipande P, Cotton B, Shintani A. Motoric sub-types of delirium in mechanically ventilated surgical and trauma intensive care unit patients, Intensive Care Med, 2007; 33(10):1726-1731.

Puntillo K. Managing Pain in the ICU Patient. Critical Care Nurse / Supplement, February 2007

Riekerk B, PenE Jand Hofhuis G. Limitations and practicalities of CAM-ICU implementation, a delirium scoring system, in a Dutch intensive care unit, Intensive Crit Care Nurs, 2009; 25:242-249.

Ringdal M, Johansson, L and undberg D. Delusional memories from the intensive care unit-experienced by patients with physical trauma. Intensive Crit Care Nurs 2006 Dec; 22(6):346-54.

Roberts B, Rickard C, Rajbhandari D, Reynolds P. Factual memories of ICU: recall at two years postdischarge and comparison with delirium status during ICU admission a multicenter cohort study. J Clin Nurs 2007; 16(9):1669-1677.

Roberts B, Rickard M and Rajbhandari D. Multicentre study of delirium in ICU patients using a simple screening tool. Aust Crit Care, 2005; 18:6-16.

Schreier A. Nursing Care, Delirium, and Pain Management for the Hospitalized Older Adult, the American Society for Pain Management Nursing, 2010; 11(3):177-185. 
Gehan A. Younis and Sabah M. Abo El-Fetoh" The Effect Of Educational ..."

Sessler CN, Gosnell M, Grap M. The Richmond Agitation-Sedation Scale: validity and reliability in adult intensive care patients, Am J Respir Crit Care Med, 2002;166: 1338-1344.

Shorr AF, White A, Dremsizov T, Schmitz R, Kelley M. Critical care delivery in the United States: distribution of services and compliance with Leapfrog recommendations, Critical Care Med, 2006; 34(4):1016-1024.

Skrobik Y, Devlin J. The intensive care delirium screening checklist has many potential benefits over the nursing delirium screening scale, Crit Care Med, 2010; 38:16101611.

Smith A. Learning styles of registered nurses enrolled in an online nursing program. J Prof Nurs. 2010; 26:49-53.
Tabet N, Howard R. Prevention, diagnosis and treatment of delirium: staff educational approaches, Expert Neurother, 2006; 6(5):741-751.

Truman B, Wesley E. Monitoring Deliriumin Critically Ill Patients Using the Confusion Assessment Method for the Intensive Care Unit. Critical Care Nurse, 2003; 23(2).

Tyler J, Leistikow, Nicole H, Laura, Krumm, Sharon K, Neufeld Karin J, Needham, A survey of nurses' perceptions of the intensive care delirium screening checklist, 2012, Canadian Association of Critical Care Nurses.

Van M, Pickkers Pand Hoeven $\mathrm{H}$. Implementation of a delirium assessment tool in the ICU can influence haloperidol use, Critical Care, 2009; 13(4): R131. 